\title{
Remission of asthma: a prospective longitudinal study from northern Europe (RHINE study)
}

\author{
M. Holm*, E. Omenaas\#, T. Gíslason`, C. Svanes\#, R. Jögi', E. Norrman", \\ C. Janson ${ }^{f}$ and $\mathrm{K}$. Torén ${ }^{* * *}$ on behalf of the RHINE study group
}

ABSTRACT: The aim of the present study was to investigate the remission rate of adult asthma in a general population sample in relation to age, sex, asthma symptoms, allergic rhinitis and smoking.

A follow-up of the random population samples from the European Community Respiratory Health Survey in Northern Europe was conducted from 1999-2001 on 1,153 individuals (aged 2653 yrs) with reported asthma. Remission was defined as no asthmatic symptoms in two consecutive years and no current use of asthma medication. Remission rates per 1,000 personyrs were calculated and Cox regression models, adjusting for confounders, were used to estimate hazard ratios (HR) with $95 \%$ confidence intervals $(\mathrm{Cl})$.

An average remission rate of $\mathbf{2 0 . 2}$ per 1,000 person-yrs was found. There was no significant difference according to sex; the remission rates were 21.7 and 17.8 per 1,000 person-yrs in females and males, respectively. An increased remission rate was observed among subjects who quit smoking during the observation period. Subjects not reporting any asthma symptom at baseline had an increased remission rate. In the Cox regression model, ex-smoking (HR 1.65, 95\% Cl 1.01-2.71) was associated with increased remission rate, and reporting any asthma symptom at baseline was associated with decreased remission rate (HR 0.7, 95\% $\mathrm{Cl}$ 0.40-0.90).

In conclusion, the present prospective longitudinal study showed that quitting smoking and the presence of mild disease appeared to favour remission.

KEYWORDS: Age, allergic rhinitis, asthma, remission, sex, smoking

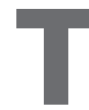
here are very few publications concerning the remission of asthma among adults. In most publications, remission of asthma is defined as absence of asthma symptoms without current pharmacological therapy. An early study from Australia found that among children who reported wheezing at baseline, $20 \%$ were in remission at the age of $21 \mathrm{yrs}$ [1] and $30 \%$ at $42 \mathrm{yrs}$ of age [2]. Several later studies showed similar results, e.g. $20-25 \%$ of subjects with asthma went into remission over a period of 20 yrs [3-5]. However, few of these studies are based on random population samples, which to some extent limit the external validity of the results.

Regarding predictors for remission of asthma, there are even fewer studies. RÖNMARK et al. [6] followed 267 adults over 10 yrs and found that $6 \%$ went into remission. Those with mild asthma had an increased "risk" of remission. In another study of Swedish children, RÖNMARK et al. [7] found that a negative skin-prick test at baseline predicted remission of asthma. In the Swedish part of the European Community Respiratory Health Survey (ECRHS), young age appeared to predict remission [8]. Follow-up of a cohort of 613 children with wheezing at baseline showed that $25 \%$ were in remission at 26 yrs of age [9]. The male sex, high age of asthma onset and normal lung function were predictors of remission.

There are no consistent definitions of asthma remission. In the Australian study, remission was defined as being free from wheeze 3 yrs before follow-up investigation [1]. BRONNIMANN and BuRROWS [3] defined remission as no medication, asthma attacks nor frequent attacks of shortness of breath with wheezing during the preceding year. PANHUYSEN et al. [5] defined "outgrown

\section{AFFILIATIONS}

Depts of ${ }^{*} 0$ ccupational and Environmental Medicine, and ${ }^{\star *}$ Respiratory Medicine and Allergology, Sahlgrenska University Hospital, Göteborg

${ }^{\text {s}}$ Dept of Pulmonary Medicine and Allergology, University Hospital of Northern Sweden, Umeå, and ${ }^{f}$ Dept of Medical Sciences, Respiratory Medicine and Allergology, Uppsala University, Uppsala, Sweden. \#Dept of Thoracic Medicine and Centre for Clinical Research, Haukeland University Hospital, Bergen, Norway.

"Dept of Pulmonary Medicine Lanspitali University Hospital,

Reykjavik, Iceland.

${ }^{+}$Foundation Tartu University Clinics, Lung Clinic, Tartu, Estonia.

\section{CORRESPONDENCE}

K. Torén, Dept of Occupational and Environmental Medicine, Box 414, SE 40530 Göteborg, Sweden. Fax: 4631409728

E-mail: Kjell.Toren@amm.gu.se

Received:

October 182005

Accepted after revision:

March 052007

SUPPORT STATEMENT

The study was supported by the Swedish Council for Worklife Research (FAS), Herman Kreftings Fund for Asthma Research, Torsten and Ragnar Söderberghs Medical Foundation, the Swedish Heart and Lung Foundation, the Norwegian Research Council, the Norwegian Asthma and Allergy Association, the Danish Lung Association and the Icelandic Research Council.

Online ISSN 1399-3003 
asthma" as no asthma symptoms, negative metacholine challenge test and normal forced expiratory volume in one second at follow-up. RÖNMARK et al. [6] defined remission of asthma as no use of asthma medicines, no recurrent wheeze and no attacks of shortness of breath at follow-up. DE MARCO et al. [10] defined remission of asthma as not having an asthma attack during the 2 yrs before follow-up and no use of asthma drugs in the last 12 months.

The present longitudinal study is a large follow-up of random population samples from the ECRHS in Northern Europe (i.e. Denmark, Estonia, Iceland, Norway and Sweden), termed RHINE (Respiratory Health in Northern Europe). The specific aim was to study the remission rate in adult subjects with asthma and to analyse the importance of certain predictors, such as age, sex, allergic rhinitis, asthma symptoms and smoking.

\section{METHODS}

The study population included 21,802 subjects born between 1945-1973 from Reykjavik (Iceland), Bergen (Norway), Umeå, Uppsala and Göteborg (Sweden), Aarhus (Denmark) and Tartu (Estonia). These individuals participated in the baseline investigation which constituted stage 1 of the ECRHS, i.e. ECRHS I [11]. Participating centres performed the baseline investigation at different years, but all centres performed it during any year between 1989-1994. All subjects answered the ECRHS screening questionnaire featuring items about asthma symptoms in the previous 12 months, such as wheezing, nocturnal chest tightness, nocturnal dyspnoea, nocturnal cough, asthma attacks, current use of asthma medication and allergic rhinitis.

At follow-up all subjects were mailed a questionnaire [12]. The centres mailed the follow-up questionnaires in different years, but all centres performed the follow-up at any year during the period 1999-2001. Hence, the observation period is slightly different between the centres, in one centre it could be 19891999 and in another centre it could be 1994-2001. Altogether $16,191(74.3 \%)$ subjects answered the questionnaire. The first part of the questionnaire contained questions identical to the original version, i.e. items about asthma symptoms [12]. A second part included items about self-reported asthma. Asthma was defined as a positive answer to either "Do you have or have you ever had asthma?" or "Have you ever had asthma diagnosed by a doctor?" [13]. The year of onset of asthma was also requested $[6,14]$.

Thus, subjects in the present analysis included those who entered the observation period with asthma (based on positive answers in the questionnaire) and those who experienced asthma onset during the observation period. Using these criteria, 1,153 individuals entered the study who either had asthma at the first survey (1989-1994) or developed asthma during the observation period. These individuals represented the study population at risk (table 1).

Remission of asthma was defined as a positive answer to the question "Which was the latest year you experienced asthma symptoms?" and no current use of asthma medication. Year of remission was obtained by adding 2 yrs to the latest year of asthma symptoms. For example, if a subject reported onset of asthma in 1986 and reported the last occurrence of symptoms in 1990, then the year of remission was 1992.

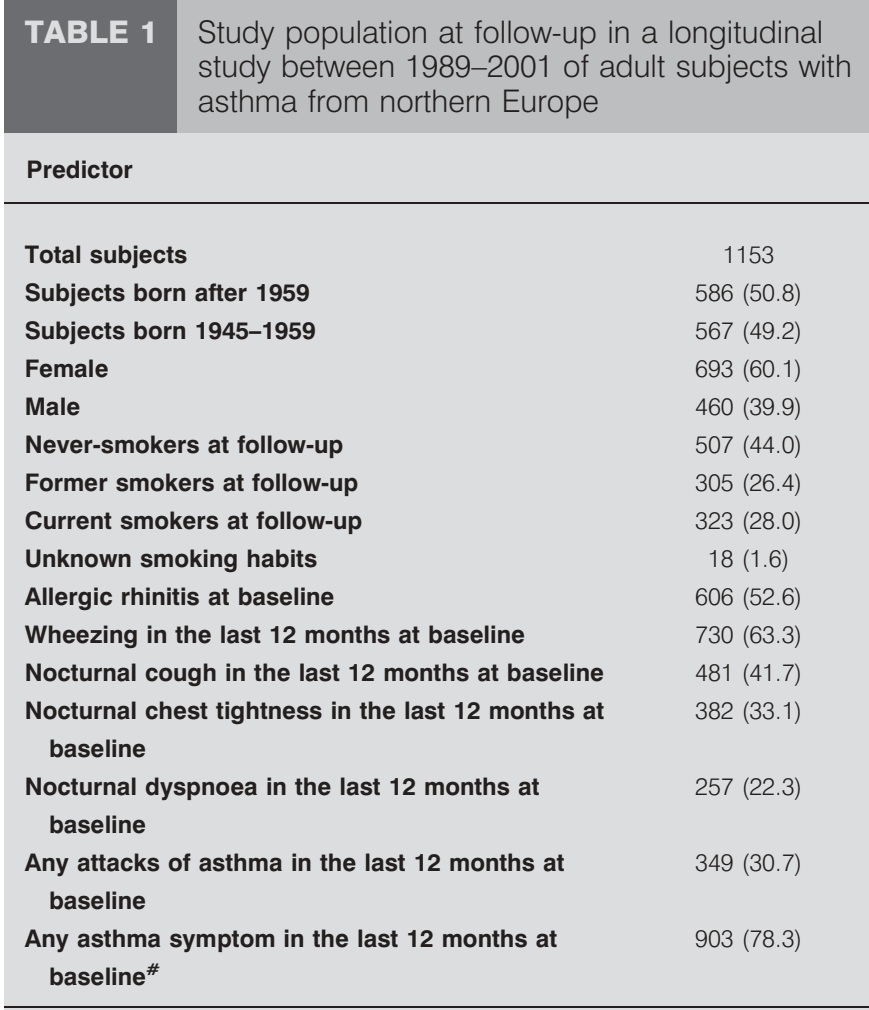

Data are presented as $\mathrm{n}$ or $\mathrm{n}(\%) .{ }^{*}$ : wheezing, asthma attacks or nocturnal cough, chest tightness or dyspnoea in the last 12 months.

Reporting, at baseline, of allergic rhinitis or any asthma symptoms (wheezing, nocturnal cough, nocturnal chest tightness, nocturnal dyspnoea or any asthma symptoms) during the last 12 months were analysed as predictors for the subsequent remission of asthma.

Smoking history at the end of follow-up was categorised as never-smoker, former smoker, current smoker or unknown. Never-smoking person-yrs were defined from the start of follow-up until the end of the observation period if the person did not start to smoke during the follow-up period. In which case, smoking person-yrs were counted from start of smoking to cessation of smoking or until the end of the observation period. If the person smoked at the start of follow-up, smoking person-yrs were defined from the start of follow-up until the end of the observation period (or until cessation of smoking). Ex-smoking person-yrs were counted from the first year after cessation of smoking.

\section{Statistical analyses}

Remission rates were calculated as the number of remissions divided by the person-yrs at risk during the observation period. The subject ceased to contribute person-yrs when remission occurred. In some analyses the subjects were divided according to the median birth year, which was 1959.

The Mantel-Haenszel method was used for the calculation of p-values. A p-value of 0.05 was regarded as significant [15]. Cox regression analyses (PROC PHREG) were performed with person-yrs under observation as the dependent variable and 
remission of asthma as an event, stratified for centre. Hazard ratios (HR) are given for explanatory variables included simultaneously in the model. In addition, there were separate models for females and males.

\section{RESULTS}

A total of 1,153 subjects entered the study, who either had asthma at baseline investigation (performed 1989-1994) or developed asthma during the observation period (1989-2001). Among these 1,153 individuals, representing a total of 10,608 person-yrs, 214 cases of asthma remission accumulated.

The remission rate was 20.2 per 1,000 person-yrs. The univariate analyses of remission rates are shown in table 2. The remission rate was decreased $(p<0.05)$ among subjects reporting any asthma symptom in the last 12 months at baseline compared with those not reporting any symptom. Subjects who quit smoking during follow-up had an increased remission rate $(\mathrm{p}<0.05)$. The remission rate among subjects with asthma onset before 20 yrs of age was 21.0 per 1,000 person-yrs compared with 19.4 per 1,000 person-yrs among those with asthma onset after 20 yrs of age.

Compared with the Swedish centres (23.6 per 1,000 person-yrs; $\mathrm{n}=118$ ) the remission rate was quite similar in Bergen (15.0 per 1,000 person-yrs; $\mathrm{n}=30$ ), Reykjavik (21.0 per 1,000 person-yrs; $\mathrm{n}=33$ ) and Aarhus (18.0 per 1,000 person-yrs; $n=22)$. However, in Tartu the remission rate was significantly $(\mathrm{p}<0.05)$ higher (61.1 per 1,000 person-yrs; $n=11$ ) compared with the Swedish centres.

The results from Cox regression models are shown in table 3. When all predictors were kept in the same model, there was a decreased remission rate among subjects reporting any asthma symptom in the last 12 months at baseline (HR 0.7, 95\%

\begin{tabular}{lcc} 
TABLE 2 & $\begin{array}{l}\text { Number of remission cases of asthma among } \\
\text { 1,153 adult asthmatic subjects from Northern } \\
\text { Europe and remission rates in relation to sex, } \\
\text { birth year, smoking and asthma symptoms at } \\
\text { baseline }\end{array}$ \\
$\begin{array}{l}\text { Predictor } \\
\text { n }\end{array}$ & Remission rate \\
\hline Females & 38 & 21.7 \\
Males & 76 & 17.8 \\
Subjects born 1960-1973 & 119 & 22.5 \\
Subjects born 1945-1959 & 95 & 17.9 \\
Smokers & 56 & 19.0 \\
Quitters & 24 & $36.9^{*}$ \\
Never-smokers & 101 & 21.7 \\
Any asthma symptom in the last $\mathbf{1 2}$ months & & \\
at baseline & & \\
Yes & 903 & 18.4 \\
No & 250 & $26.5^{\circ}$ \\
\hline
\end{tabular}

Remission rate is presented as cases per 1,000 person-yrs under observation. \# : these are subjects who quit smoking during the observation period. Subjects who quit smoking before the first survey are not included; ${ }^{\bullet}: p<0.05$ yes versus no. *: $p<0.05$ compared with never-smokers.

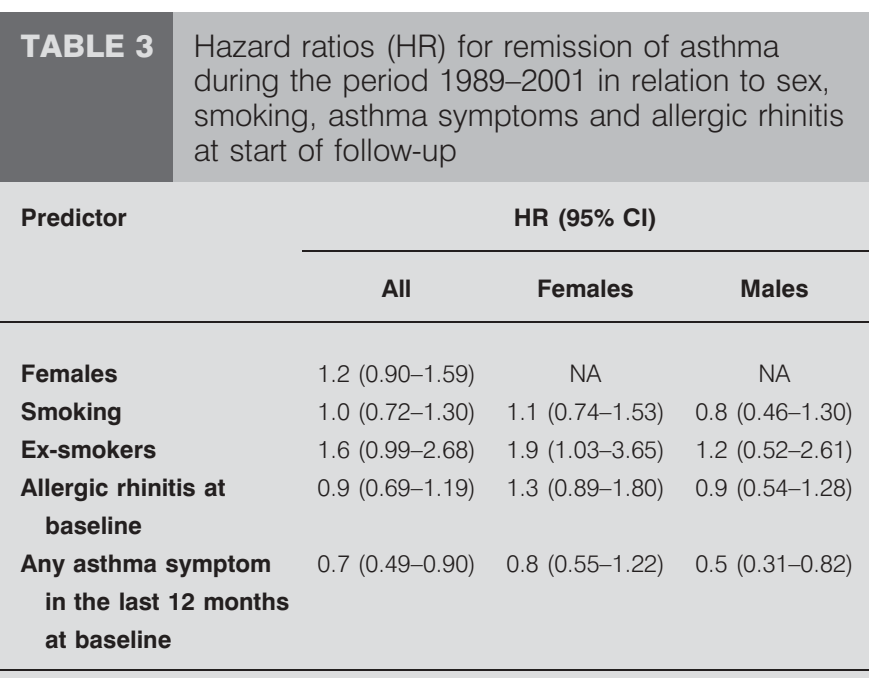

Smoking is analysed as a time dependent variable. Results are based on a Cox regression model adjusted for centre and birth year. $\mathrm{Cl}$ : confidence interval; NA: not available.

confidence interval (CI) 0.49-0.90). Among ex-smokers there was an increased remission rate among females (HR 1.9, 95\% CI 1.03-3.65), but not among males. If year of asthma onset was introduced to the models, the results were similar.

\section{DISCUSSION}

In the present prospective longitudinal study, the remission rate of asthma was found to be 20.2 per 1,000 person-yrs during the period 1989-2001, i.e. $\sim 20 \%$ of subjects recovered from their asthma during a $10-y r$ period. A main finding was that subjects with asthma who reported asthma symptoms at baseline were less likely to recover from their asthma (i.e. subjects with a less severe asthma had an increased remission rate).

There are few studies on remission of asthma among adults. Several quite different definitions of remission have been used, which may partly explain the varying results between studies. In the present study, remission was defined as no current use of asthma medication and no asthmatic symptoms during the last 2 yrs.

One of the few studies on asthma remission rate in adults investigated a cohort of 300 middle-aged and elderly subjects [7]. This study reported remission (no use of asthma medicines, no recurrent wheezing and no attacks of shortness of breath) in $6 \%$ of subjects at a follow-up 10 yrs after a validated diagnosis of current asthma, equivalent to a remission rate of six per 1,000 person-yrs. In 60 subjects with suspected asthma, $22 \%$ were in remission at the $10-y$ followup. The study concluded that remission was associated with mild disease.

The present study found that subjects reporting symptoms at baseline had decreased probability of remission during the follow-up. An obvious explanation is that subjects with mild disease have an increased probability of remission. Similar observations have also been published by other groups $[3,5-6]$. 
The current authors did not find any relationship between remission and either birth year or age of asthma onset. The present study focused on asthma remission in a population of adults born between 1945-1973. Most published studies indicate that remission is most common in younger individuals $[2,5,16,17]$. One study found that the remission rate was highest in subjects aged $<30$ yrs at entry and lowest in those aged 30-59 yrs. However, in subjects aged $>60$ yrs the remission rate increased [3]. In an Italian study, remission was strongly influenced by the age at onset of asthma, with a stepwise decreasing probability of remission from $0-44$ yrs of age [10]. Moreover, it was found that remission appears to occur principally during the first years after the onset of the disease. In the present study, there was a tendency for subjects born after 1959 to have a higher remission rate than subjects born between 1945-1959; this is in agreement with previous studies. The current authors did not observe any difference with regard to age of asthma onset, as the remission rate among subjects with asthma onset before 20 yrs was similar to those with asthma onset after 20 yrs of age.

The relationship between smoking and asthma is complex. However, in the present analysis quitting smoking was found to favour remission of asthma. This finding is supported by RÖNMARK et al. [7], who concluded that remission of asthma is associated with cessation of smoking.

The present study has two key strengths: its size and its welldefined population. Out of 1,153 asthmatic individuals, 214 were considered to be in a state of remission, resulting in one of the largest ever studies examining asthma remission and its predictors. As discussed in a previous paper, a weakness of the study is that diagnostic traditions appear to differ between countries [12]. However, this was not reflected in the remission rate in Iceland, which was similar to that of other countries, despite less severe cases receiving a physician's diagnosis of asthma. In Estonia, it has been previously observed that individuals diagnosed with asthma may have a severe disease [12]. Nonetheless, Estonia had a high remission rate in the present study. The current authors have no explanation for this unexpected observation.

A weakness of the study is that it is based on self-reported data. Self-reported, physician-diagnosed asthma is biased towards severity, i.e. subjects with mild asthma are more prone to deny asthma [18]. Hence, the estimations of remission rate are probably underestimating the true remission rate, as subjects with mild disease are underrepresented among asthmatics.

In conclusion, the main observation of the present study is that smoking cessation favoured remission. This further strengthens the importance of implementing smoking cessation programmes among subjects with asthma.

\section{REFERENCES}

1 Martin AJ, McLennan LA, Landau LI, Phelan PD. The natural history of asthma to adult life. Br Med J 1980; 280: 1397-1400.
2 Phelan PD, Robertson CF, Olinsky A. The Melbourne Asthma Study: 1964-1999. J Allergy Clin Immunol 2002; 109: 189-194.

3 Bronnimann S, Burrows B. A prospective study of the natural history of asthma. Remission and relapse rates. Chest 1986; 90: 480-484.

4 Roorda RJ, Gerritsen J, van Aalderen VM, et al. Risk factors for the persistence of respiratory symptoms in childhood asthma. Am Rev Respir Dis 1993; 148: 1490-1495.

5 Panhuysen CI, Vonk JM, Koeter GH, et al. Adult patients may outgrow their asthma: a 25-year follow-up study. Am J Respir Crit Care Med 1997; 155: 1267-1272.

6 Rönmark E, Jönsson E, Lundbäck B. Remission of asthma in the middle aged and elderly: report from the Obstructive Lung Disease in Northern Sweden study. Thorax 1999; 54: 611-613.

7 Rönmark E, Jönsson E, Platts-Mills T, Lundbäck B. Incidence and remission of asthma in schoolchildren: report from the Obstructive Lung Disease in Northern Sweden studies. Pediatrics 2001; 107: E37.

8 Plaschke PP, Janson C, Norrman E, Björnsson E, Ellbjär S, Järvholm B. Onset and remission of allergic rhinitis and asthma and the relationship with atopic sensitization and smoking. Am J Respir Crit Care Med 2000; 162: 920-924.

9 Sears MR, Greene JM, Willan AR, et al. A longitudinal, population-based cohort study of childhood asthma followed to adulthood. N Engl J Med 2003; 349: 1414-1422.

10 De Marco R, Locatelli F, Cerveri I, Bugiani M, Marinoni A, Giammanco G, Italian Study on Asthma in Young Adults study group. Incidence and remission of asthma: a retrospective study on the natural history of asthma in Italy. J Allergy Clin Immunol 2002; 110: 228-235.

11 Janson C, Anto J, Burney P, et al. The European Community Respiratory Health Survey: what are the main results so far? Eur Respir J 2001; 18: 598-611.

12 Toren K, Gislason T, Omenaas E, et al. A prospective study of asthma incidence and its predictors: the RHINE study. Eur Respir J 2004; 24: 942-946.

13 Toren K, Brisman J, Järvholm B. Asthma and asthma-like symptoms in adults assessed by questionnaires. A literature review. Chest 1993; 104: 600-608.

14 Andersson E, Knutsson A, Hagberg S, et al. Incidence of asthma among workers exposed to sulphur dioxide and other irritant gases. Eur Respir J 2006; 27: 720-725.

15 Altman DG. Practical Statistics for Medical Research. London, Chapman and Hall, 1991.

16 Kelly WJ, Hudson I, Phelan PD, Pain MC, Olinsky A. Childhood asthma in adult life: a further study at 28 years of age. Br Med J (Clin Res Ed) 1987; 294: 1059-1062.

17 Strachan DP, Butland BK, Anderson HR. Incidence and prognosis of asthma and wheezing illness from early childhood to age 33 in a national British cohort. BMJ 1996; 312: 1195-1199.

18 Torén K, Palmqvist M, Löwhagen O, Balder B, Tunsäter A. Self-reported asthma was biased in relation to disease severity while reported year of asthma onset was accurate. J Clin Epidemiol 2006; 59: 90-93. 